\title{
KEMAMPUAN MENULIS KARYA SASTRA BERBAHASA JERMAN MAHASISWA PROGRAM STUDI PENDIDIKAN BAHASA JERMAN FBS UNM (KAJIAN STRUKTURAL)
}

\author{
Burhanuddin $^{1}$, Susiawati ${ }^{2}$, dan Ernawati ${ }^{3}$ \\ Jurusan Pendidikan Bahasa Asing \\ Fakultas Bahasa dan Sastra Universitas Negeri Makassar \\ Email ${ }^{1}$ : burhangage@gmail.com
}

\begin{abstract}
ABSTRAK
Penelitian ini menggunakan desain deskriptif kualitatif yang bertujuan untuk mendeskripsikan kemampuan menulis cerita pendek bahasa Jerman mahasiswa program studi pendidikan bahasa Jerman. Populasi dalam penelitian ini ialah cerita pendek yang ditulis oleh mahasiswa. Penelitian ini melibatkan 2 kelas, kelas A yang terdiri dari 31 siswa, dan kelas B yang terdiri atas 24 siswa. Analisis data dalam penelitian ini yakni analisis struktural untuk mendeskripsikan strktur atau elemen internal dari cerita. Hasil penelitian menunjukkan bahwa kemampuan mahasiswa dlaam menulis cerita pendek berada pada kategori baik.
\end{abstract}

Kata Kunci: Menulis. Cerita Pendek, dan Analisis Struktural

\begin{abstract}
The study is descriptive qualitative design, that aims to describe the ability in writing of German literary works student of German Language Study Program. The population in this study is the german short story, which was written by students. This study consists of 2 classes, A Class are 31 students and B Class are 24 students. Structural analysis is used the research hypotheses, to analysed the structure of the story (intrinsic element. The result of this study is to describe, that the ability in writing short story (Kurzgeschichte) students of German Languange Study Program FBS UNM was in good level.
\end{abstract}

Keywords: writing, short story, and Structural Analysis

\section{PENDAHULUAN}

Bahasa Jerman merupakan salah satu bahasa yang paling banyak dipakai di dunia setelah bahasa Inggris. Kecakapan berbahasa Jerman akan membantu kita sukses di bidang bisnis global, ekonomi dan industri internasional. Di Indonesia bahasa Jerman mulai diperkenalkan pada institusi pendidikan pada tingkatan Sekolah-sekolah
Menengah Atas (SMA) dan institusi Perguruan Tinggi (PT), baik negeri maupun swasta.

Keterampilan menulis dalam bahasa Jerman menjadi sangat penting karena memerlukan penguasaan semua unsur keterampilan berbahasa lainnya. Untuk menghasilkan sebuah tulisan, seringkali pelajar mengalami kesulitan, karena seolaholah harus melalui proses yang panjang, 
misalnya mengecek ketepatan penggunaan struktur kalimat, kosakata, dan gramatiknya.

Dalam mempelajari suatu bahasa asing, tidak cukup hanya dengan mempelajari bahasanya saja, tetapi juga diperlukan pemahaman lainnya, baik tentang sejarah, ekonomi, politik, sosial, budaya serta kesusastran dari Negara tersebut.

Dengan membaca karya sastra diharapkan seseorang memiliki pengertian yang baik tentang manusia dan kemanusiaan, mengenal nilai, mendapatkan ide-ide baru dan untuk mencapai kemampuan apresiasi kreatif. Widdowson (1997: 83) mengungkapkan bahwa "Pengajaran sastra ditujukan agar pelajar terdidik menjadi manusia berkepribadian sopan dan beradab, berbudi pekerti yang halus, memiliki rasa kemanusian, berkepribadian sosial, memiliki apresiasi budaya dan penyaluran gagasan,berimajinasi berekspresi secara kreatif, baik secara lisan maupun tertulis. Tujuan yang lainnya yaitu untuk meningkatkan kemampuan pelajar dalam menikmati, menghayati dan memahami karya sastra" (Ernawati, 2009: 4).

Menulis cerpen dalam bahasa Jerman merupakan salah satu cara untuk meningkatkan penguasaan keterampilan berbahasa Jerman, khususnya keterampilan menulis. Dengan menulis cerpen akan menstimulus munculnya ide-ide imajinatif dan kreatif dari seseorang, baik yang diperoleh dari pengalaman sendiri maupun dari sekelilingnya, yang kemudian dituangkan menjadi sebuah cerita.

Penelitian tentang keterampilan menulis yang pernah dilakukan oleh Masrurih (2009) menunjukkan bahwa pembelajaran menulis cerpen dengan metode Copy the Master pada siswa MTs Al Huda di Malang dengan menggunakan metode analisis struktur, memberikan beberapa manfaat antara lain (i) meningkatkan minat baca siswa terhadap karya sastra, khususnya cerpen, (ii) meningkatkan kemampuan siswa dalam keterampilan menulis cerpen, (iii) dapat dijadikan alternatif oleh guru untuk pembelajaran menulis cerpen. Selanjutnya, penelitian yang dilakukan oleh Tatag (2014) dengan metode analisis strukturalisme dalam cerita pendek "Die Postkarte" karya Heinrich Böll mengungkapkan bahwa keterkaitan antara unsur intrinsik cerpen, dimana tema, tokoh, latar ruang dan waktu, menunjukkan sebuah struktur yang saling mempengaruhi satu sama lain, yang tidak dapat dipisahkan satu sama lain.

Berdasakan latar belakang di atas, maka penelitian ini menganalisis bagaimana kemampuan menulis cerita pendek (Kurzgeschichte) dalam bahasa Jerman mahasiswa Program Studi Pendidikan Bahasa Jerman FBS UNM (Kajian Struktural).

\section{HAKIKAT MENULIS}

Karagiannakis mengungkapkan bahwa "Schreiben bedeutet, viele kleine Schritte nacheinander bewusst zu gehen". Dapat diartikan bahwa menulis berarti, banyak langkah kecil yang secara sadar saling berkaitan. Dapat disimpulkan bahwa dalam menulis, secara sadar atau tidak sadar melewati berbagai langkah kecil yang saling berkaitan antar satu dengan yang lain. Yang dimaksud langkah kecil adalah proses berpikir, proses mengabadikan tulisan serta 
proses menyusun bahasa ke tulisan. (Rosalina, 2014: 16)

Morsey menyatakan bahwa "Menulis dipergunakan oleh pelajar untuk mencatat/merekam, melaporkan, meyakinkan dan mempengaruhi, dan maksud serta tujuan seperti itu hanya dapat dicapai dengan baik oleh orang-orang yang dapat menyusun pikirannya dan mengutarannya dengan jelas, kejelasan ini tergantung pada pikiran, organisasi, pemakaian kata-kata, struktur kalimat" (Ernawati, 2009: 6)

Dari beberapa pendapat di atas, dapat disimpulkan bahwa menulis adalah mengungkapkan ide, pikiran dan perasan dalam bentuk tulisan, ke dalam lambanglambang kebahasaan yang saling berkaitan antara satu dengan yang lainnya, untuk meyakinkan suatu maksud dan tujuan untuk menjadikan semua itu sebagai sesuatu yang bermakna bagi manusia yang memiliki kesadaran eksistensial.

\section{CERITA}

PENDEK

\section{(KURZGESCHICHTE)}

Pengertian cerita pendek dalam Duden (2000: 98) menyatakan bahwa "Eine Kurzgeschichte zeichnet sich durch einen sehr konzentrieren Erzählverlauf aus. Anfang und Ende sind stark pointiert". Dapat diartikan bahwa cerita pendek ditandai dengan pengkonsentrasian jalan ceritanya. Penempatan cerita tanpa pendahuluan di tengah-tengah cerita. Pada awal dan akhir cerita lebih dipertajam.

Menurut Haerkötter dalam Tatag (2014:2) cerpen adalah sebuah karya sastra modern yang berkembang di Jerman pada masa setelah Perang Dunia ke II. Sebuah alur dan jalan cerita yang tegas serta memilki rangka yang terstruktur menjadi penanda sebuah cerita pendek. Ciri-ciri cerpen adalah tidak ada pembukaan dan berakhir dengan mengambang. Hal ini dapat diartikan bahwa cerita dalam cerpen langsung menuju pada inti cerita dan akhir dalam cerita pendek tersebut masih menyisahkan pertanyaan bagi para pembacanya.

Dari beberapa pendapat di atas dapat disimpulkan bahwa cerita pendek adalah karya sastra berbentuk prosa atau cerita, yang mengkonsentrasikan ceritanya hanya pada satu kejadian atau peristiwa saja. Cerita pendek terdiri dari beberapa unsur diantaranya seperti:

\section{Alur/Plot (Handlung)}

Alur cerita merupakan kejadian atau peristiwa yang berlangsung dari awal hingga akhir cerita. Pengertian lain tetntang alur mengungkapkan bahwa "Die Umstände der Handlung sind knapp, aber präzise skizziert”. (Duden, 2000; 98). Dapat diartikan bahwa keadaan suatu alur atau sekuen adalah terbatas, tetapi dirancang dengan tepat.

\section{Tokoh dan Penokohan (Personen/Figuren)}

Tokoh cerita adalah pelaku yang terdapat dalam cerita, yang merujuk pada siapa yang melakukan sesuatu atau dikenai sesuatu. Tokoh cerita kadangkala merupakan pembawa pesan, amanat, moral, atau sesuatu yang sengaja ingin disampaikan kepada pembaca.

Penokohan merupakan pelukisan gambaran yang jelas tentang seseorang yang ditampilkan, yang menyaran pada tehnik perwujudan dan penggambaran tokoh dalam sebuah cerita. Tokoh dalam cerita dibedakan 
atas tokoh utama dan tokoh tambahan. Tokoh utama yaitu tokoh yang diutamakan penceritaanya dan juga tokoh yang paling banyak diceritakan dan mempengaruhi perkembangan plot. Sedangkan tokoh tambahan merupakan tokoh yang porsi penceritaannya relatif singkat, yang berfungsi mendukung keberadaan rokoh utama serta wataknya tidak berubah atau statis.

\section{Latar/Setting (Ort)}

Latar adalah tempat, hubungan, waktu dan lingkungan sosial tempat terjadinya peristiwa dalam cerita. Latar memberikan kesan realitas pada pembaca, menciptakan suasana tertentu yang seolaholah benar-benar terjadi.

\section{Sudut Pandang (Erzählperspektive)}

Sudut pandang dalam sebuah karya fiksi mempersoalkan tentang siapa yang menceritakan, atau dari posisi mana (siapa) peristiwa atau tidandakan dalam cerita dilihat. Sudut pandang pada hakikatnya adalah sebuah strategi, tehnik, siasat, yang sengaja dipilih pengarang untuk menyampaikan gagasan dan ceritanya.

Sudut pandang berdasarkan tingkat kebebasan dan keterikatan ceritanya yaitu sudut pandang mahatahu (Autorial) dan sudut pandang terbatas atau berjarak (Netral). Sudut pandang mahatahu mengungkapkan semua hal tentang tokoh, peristiwa, tindakan serta motivassi yang melatarbelakanginya bergerak bebas dan menceritakan apa saja dalam lingkup waktu dan cerita. Sedangkan sudut pandang terbatas mencakupi hal-hal secara terbatas, hanya melukiskan apa yang terlihat, terdengar, atau apa yang dialami, dipikirkan dan dirasakan oleh tokoh sesuai pengetahuannya.

\section{Tema dan Amanat (Theme)}

Tema adalah kesatuan ide atau gagasan yang mendasari cerita. Permasalahan yang diangkat dalam tema yaitu tentang kehidupan manusia. Muakhir (2008: 18) menyatakan bahwa "Tema tulisan bermacam-macam. Dari segi ceritanya, tema dibagi menjadi tema misteri, drama, humor/komedi, dan futuristik (masa depan) atau fiksi ilmiah (science fiction). Dari segi isi cerita, yaitu tema persahabatan, tema sosial, tema ilmu pengetahuan dan sebagainya".

\section{METODE PENELITIAN}

Desain penelitian ini menggunakan desain deskriptif kualitatif, dengan tujuan untuk menggambarkan kemampuan menulis cerita pendek dalam bahasa Jerman mahasiswa Pogram Studi Pendidikan Bahasa Jerman FBS UNM.

Variabel penelitian ini adalah kecakapan mahasisiswa untuk menulis atau menciptakan cerita pendek dalam bahasa Jerman dalam bentuk tertulis. Populasi penelitian ini adalah cerita pendek dalam bahasa Jerman yang telah ditulis oleh mahasiswa Program Studi Pendidikan Bahasa Jerman FBS UNM. Sampel penelitian adalah mahasiswa Jurusan Pendidikan Bahasa Asing/Bahasa Jerman Angkatan 2013, Kelas A sebanyak 31 orang dan Kelas B sebanyak 24 orang.

Tehnik pengumpulan data penelitian ini adalah meminta mahasiswa menuliscerita pendek dalam bahasa Jerman dengan tema bebas. Data-data penelitian yang telah 
dikumpulkan, selanjutanya akan diklasifikasikan berdasarkan kategorinya. Hasil pengkalsifikasian data ini yang akan dianalisis. Pertama data dianalisis dengan tehnik persentase untuk mengetahui kemampuan rata-rata mahasiswa dalam menulis cerita pendek dlam bahasa Jerman. Selanjutnya data dianalisis dengan metode analisis structural, yakni mengalisis alur, tokoh dan latar dalam cerita pendek ini.

\section{HASIL DAN PEMBAHASAN}

Hasil analisis tentang kemampuan menulis cerita pendek (Kurzgeschichte) dalam bahasa Jerman mahasiswa Program Studi Pendidikan Bahasa Jerman FBS UNM, berdasarkan metode persentase adalah (1) aspek kelengkapan formal cerpen adalah pada kategori sangat baik (100\%); (2) aspek kelegkapan unsur intrinsik adalah pada kategori baik $(78,26)$; (3) aspek keterpaduan/struktur adalah pada kategori baik $(69,57)$; (4) aspek kesesuaian bahasa cerpen adalah pada kategori cukup $(60,87)$; dan secara umum kemampuan menulis cerpen mahasiswa Program Studi Pendidikan Bahasa Jerman FBS UNM adalah pada kategori baik $(77,39)$.

Kesatuan makna yang digambarkan dalam cerita pendek dengan judul "Sauber Liebe" (Cinta Suci) mengungkapkan bahwa cinta suci adalah ketika bisa saling menjaga dan melindungi satu sama lain. Sebagai manusia biasa pasti ingin selalu dicintai dan mencintai. Cerita pendek ini mengisahkan kisah cinta dua remaja yang mencari cinta suci. Kedua tokoh utamanya tidak bisa menghindari pesona cinta yang menggelora. Ungkapkan rasa pun terungkap melalui goresan pena, yang dibingkai dengan indah dan puitis. Kebimbangan dalam memilih cita-cita, cinta dan syariat, pada akhirnya mengantar pada suatu keputusan memilih cita-cita untuk mencapai masa depan yang lebih baik dan juga lebih mendekatkan diri kepada sang pencipta untuk meredam nafsu cinta yang tumbuh di hati. Penantian dan harapan adalah sebuah proses menuju cinta suci yang diridhoi Ilahi.

Kesatuan makna yang digambarkan dalam cerita pendek ke dua dengan judul "Wunsch" (Keinginan) adalah cinta sejati yang terjaga sampai akhir hayat. Cinta sejati tidak dapat diukur hanya dengan ungkapan sayang saja atau pun dengan ikatan pernikahan saja, tetapi bagaimana mempertahankan semuanya dengan kasih sayang, perhatian dan pengertian sampai maut memisahkan keduanya. Makna cerita yang terungkap lainnya yaitu keinginan yang terwujud melalui doa. Keinginan untuk selalu bersama bahkan setelah maut memisahkan kedua tokoh cerita, yang tidak terbatas oleh ruang dan waktu. Makna yang juga terungkap dalam cerita pendek ini yaitu hubungan antara orang tua, anak dan cucu, yang saling memberikan semangat untuk menunjukkan kasih sayang dalam sebuah keluarga.

Kesatuan makna yang terungkap dalam cerita pendek "Die beste Schmuck in der Welt" (Sebaik-baik perhiasan dunia) menunjukkan bahwa inspirasi atau hidayah bisa datang dari sisi mana saja, terutama dari lingkungan pergaulan, baik dari pengalaman pribadi maupun dari pengalaman orang lain. Hal tersebut membutuhkan waktu dan proses, tetapi ketika lebih dipahami dengan 
lebih mendalam maka akan mendapatkan manfaat yang lebih baik. Seorang wanita muslimah merupakan sosok menawan, yang terlahir dengan kelebihan dan keistimewaan rupa yang jelita. Agama islam sangat menjaga eksistensi muslimah dalam kehidupan ini, salah satunya dengan diturunkannya ayat-ayat Ilahi berupa perintah menutup aurat bagi wanita agar senantiasa terjaga dan terawat untuk melindungi wanita agar selamat dunia akhirat. Salah satu kewajiban seorang muslimah adalah menutup auratnya, tetapi fenomena yang terjadi saat ini adalah banyak yang berhijab hanya karena ikut-ikutan trend masa kini atau hanya digunakan sebagai penutup kepala saja dan melupakan bahwa kewajiban seorang muslimah seharusnya mengulurkan hijabnya ke seluruh tubuh dan tidak menampakkan "perhiasannya".

Hijab syar'i merupakan mode hijab berupa gamis panjang dengan bahan yang tebal dipadukan dengan jilbab panjang hingga membuat lekuk tubuh wanita tertutup. Beberapa syarat dari hijab syar'i antara lain, bahwa pakaian wanita harus menutupi seluruh tubuh kecuali wajah dan telapak kaki, pakaian tidak tipis serta tidak tembus pandang, serta tidak bertabarruj atau perilaku wanita yang menampakkan perhiasan dan kecantikannya, serta segala sesuatu yang seharusnya ditutup karena hal tersebut dapat menggoda kaum laki-laki. Maksud perintah mengenakan hijab sesuai dengan tuntunan syariat, mengungkapkan bahwa kewajiban bagi setiap muslimah yang harus dipelajari dan diperjuangkan penerapannya dan yang paling utama bagi seorang muslimah adalah kembali kepada makna dari teks dan kontekstual Alquran terhadap hijab syar'I agar tidak ada prasangka, sehingga menjadi wanita yang sesungguhnya dengan kesempurnaan hijab. Makna lainnya yang digambarkan dalam cerita pendek ini adalah pencarian identitas diri menuju jalan yang lebih baik serta keteguhan hati tokoh menjaga prinsip untuk selalu menjaga auratnya sampai maut menjemputnya.

Persamaan ketiga cerita pendek di atas adalah cerita-cerita di atas juga mengungkapkan makna kereligiusan tokohtokoh utamanya, yang mampu mempertahankan prinsip dalam menemukan dan mencapai tujian yang lebih baik. Cerpen "Sauber Libe" menggambarkan rasa cinta kepada sang maha pencipta lebih besar dari pada rasa cintanya kepada sang kekasih, yang membawanya lebih mendekatkan diri kepada sang maha kuasa. Cerita pendek "Wunsch" menunjukkan cinta sejati dunia dan akhirat, yang tidak terbatas ruang dan waktu. Cerita pendek yang ketiga "Die beste Schmuck in der Welt" mengungkapkan hijrah tokoh untuk menemukan identitas yang lebih baik serta keteguhan hati seorang muslimah menjaga auratnya. Persamaan makna lainnya yaitu tokoh-tokoh dalam ketiga cerita pendek di atas digambarkan memiliki latar belakang keagaamaan yang kuat, dimana tokoh utama dalam cerpen "Sauber Liebe" adalah seorang santri di sebuah pesantren. Tokoh utama cerpen "Wunsch" merupakan seorang imam mesjid serta tokoh utama dalam cerpen "Die beste Smuck in der Welt" berlatar belakang seorang wanita yang sebelumnya masih memakai hijab modern, kemudian berhijrah untuk memakai jilbab yang lebih syar'i. 
Berdasarkan hasil analisis data penelitian dan pembahasan di atas menunjukkan hasil kemampuan menulis cerita pendek dalam bahasa Jerman mahasiswa Pendidikan Bahasa Jerman FBS UNM berdasarkan analisis/kajian struktural adalah cukup baik. Cerita pendek dalam penelitian ini telah memenuhi unsur-unsur dalam kriteria penilaian sebuah cerita pendek, seperti kelengkapan aspek formal cerpen, yang meliputi judul, nama pengarang, dialog dan narasi. Kelengkapan unsur intrinsik cerpen, yang memuat fakta cerita (plot, tokoh dan latar), sarana cerita (sudut pandang, penceritaan, gaya bahasa, simbolisme, dan ironi), serta pengembangan tema yang relevan dengan judul. Selanjutnya kriteria penilaian keterpaduan unsur/struktur cerpen, yang mencakup (kaidah plot, kelogisan, rasa ingin tahu, kejutan dan keutuhan), penahapan plot (awal, tengah dan akhir), dimensi tokoh (fisiologis, psikologis dan sosiologis), dimensi latar (tempat, waktu dan sosial). Tetapi, dalam kriteria kesesuaian penggunaan bahasa cerpen seperti kaidah EYD, keajekan penulisan, ragam bahasa, serta penggunaan struktur dan gramatik penulisan masih perlu ditingkatkan dalam penulisan sebuah cerita pendek ini.

\section{KESIMPULAN}

\begin{abstract}
Kemampuan menulis cerita pendek (Kurzgeschichte) berbahasa Jerman mahasiswa Pendidikan Bahasa Jerman FBS UNM dengan menggunakan analisis struktural menunjukkan hasil yang cukup baik. Hal tersebut dibuktikan dengan hasil analisis struktural (Alur penyajian, tokoh, latar ruang dan waktu cerita) tiga cerita
\end{abstract}

pendek yang telah dipilih dengan judul "Sauber Liebe" (Cinta Suci), "Wunsch" (Keinginan), "Die beste Schmuck in der Welt” (Sebaik-baik Perhiasan Dunia).

Hasil analisis data penelitian dan pembahasan di atas menunjukkan hasil kemampuan menulis cerita pendek dalam bahasa Jerman mahasiswa Pendidikan Bahasa Jerman FBS UNM berdasarkan analisis/kajian struktural adalah cukup baik. Cerita pendek dalam penelitian ini telah memenuhi unsur-unsur dalam kriteria penilaian sebuah cerita pendek, seperti kelengkapan aspek formal cerpen, yang meliputi judul, nama pengarang, dialog dan narasi, kelengkapan unsur instrinsik cerpen, yang memuat fakta cerita dan pengembangan tema yang relevan dengan judul serta kriteria penilaian keterpaduan unsur/struktur cerpen, plot, dimensi tokoh, dimensi latar.

\section{DAFTAR PUSTAKA}

Brannen, Julia. 2002. Memadu Metode Penelitian. Kualitatif \& Kuantitatif. Samarinda: Pusaka Pelajar

Budianta, Melani. Ida Sundari Husen. Manekke Budiman \& Ibnu Wahyudi. 2008. Membaca Sastra. Pengantar Memahami Sastra untuk Perguruan Tinggi. Jogja: Indonesiatera

Duden. 2000. Basiswissen Schule. Literatur. Berlin: Paetec

Ernawati. 2009. Kemamapuan Menulis Puisi dalam Bahasa Jerman Mahasiswa Program Studi Pendidikan Bahasa Jerman. Kajian Analisis Isi. Makassar: Skripsi 
Ernawati. 2011. Makna Merpati dalam Novel Die Taube Karya Patrick Süskind. Kajian Psikoanalisis. Depok. Tesis

Kompak, Abiwissen. 2008. Deutsch. Prosa/Drama/Lyrik. Stuttgart: Ernst Klett Verlag

Kridalaksana, Harimukti. 2005. MonginFedinand de Saussure. Peletak Dasar Strukturalisme dan Linguistik Modern. Jakarta: Yayasan Obor Indonesia

Masrurih. 2009. Pemebelajaran Menulis Cerita Pendek dengan Metode Copy the Master pada Siswa Madrasah Tsanawiyah Al Huda Di Malang Jawa Timur. Depok. Tesis

Muakhir, Ali. 2008. Fun Writing. Panduan Menulis utuk Anak-anak. Jakarta: Sarana Bobo

Nurgiantoro, Burhan. 2010. Teori Pengkajian Fiksi. Yogayakarta: Gadjah Mada University Press

Pradopo, Rahmat Djoko. 2002. Kritik Sastra Indonesia Modern. Yogyakarta. Gama Media

Rosalina, Praeska Andre. 2014. Keefektifan Metode Estafet Writing dalam Pembelajaran Keterampilan Menulis Bahasa Jerman Peserta Didik Kelas XII di SMA Negerei I Sedayu bantul. Yogyakarta: Skripsi

Tatag P, Agustinus Dimas. 2014. Analisis Strukturalisme dalam Cerita Pendek "die Postkarte" karya Heinrich Böll. Universitas Negeri Yogyakarta: Skripsi

Zaimar, Okke K S. 2008. Semiotik dan Penerapannya dalam Karya Sastra.
Jakarta: Pusat Bahasa Departemen Pendidikan Nasional 